\title{
SURGICAL TREATMENT OF ANORECTAL ANOMALIES IN CHILDREN: EXPERIENCE WITH 224 PATIENTS
}

\section{HIRURŠKO LEČENJE ANOREKTALNIH ANOMALIJA KOD DECE: ISKUSTVO NA 224 PACIJENTA}

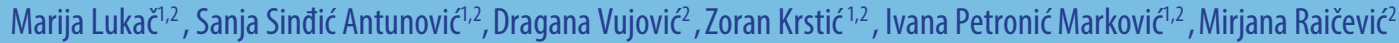

\section{Summary}

Anorectal anomalies (ARA) are congenital malformations that are represented by a wide spectrum of defects. This report describes the authors' experience and results of surgical treatment of ARA. The aim of this study was to analyse the functional outcome in patients following standardized surgical treatment of ARA.

A total of 224 patients (115 girls and 109 boys) were treated from 1988 to 2015 and the data were analysed. All patients underwent a follow up by the author. Postoperative anorectal function was evaluated based on the ability to have voluntary bowel movement, soiling and constipation. In cases of faecal incontinence bowel management program was applied.

In our series of 224 operated patients 52 (24\%) had faecal incontinence. Bowel management program was implemented in those patients, with a success rate of $90,6 \%$ immediately after the treatment started in hospital, with a decrease to $83,7 \%$ at home. In puberty success rate increased to $95 \%$. Malone's antegrade enema procedure (ACE procedure) was done in 9 patients. It was successful in $100 \%$ of cases in the first year, with complication rate of $44 \%$ afterwards (conduit stenosis and leakage).

Bowel management program offers significant benefits to children with faecal incontinence after surgical treatment of ARA. The ACE procedure can be implemented in patients after successful bowel management. Although patients are satisfied with ACE procedure, complications are very common.

Keywords: anorectal anomalies, outcome, bowel management, ACE procedure.

\section{Sažetak}

Anorektalne anomalije (ARA) su kongenitalne malformacije koje čine širok spektar poremećaja. Ovaj rad opisuje autorovo iskustvo i rezultate hiruř̌̌kog lečenja ARA. Cilj ovog ispitivanja je bila analiza funkcionalnog ishoda u pacijenata nakon standardnog hiruřškog lečenja ARA.

Od 1988. do 2015. je ukupno lečeno 224 pacijenata (115 devojčica i 109 dečaka) i njihovi podaci su analizirani. Svi pacijenti su praćeni od strane autora. Postoperativno je praćena anorektalna funkcija bazirana na sposobnosti voljnog pražnjenja creva, prljanja veša i opstipacije. U slučajevima fekalne inkontinencije primenjen je program tretmana creva (bowel management).

U našoj seriji 224 operisana pacijenta 52 (24\%) je bilo fekalno inkontinentno. Program tretmana creva je bio primenjen kod tih pacijenata, sa uspešnošću od 90,6\% neposredno nakon što je lečenje završeno u bolnici, a uspešnosti kod kuće se smanjila na $83,7 \%$. U vreme puberteta uspešnost tretmana creva je porasla na 95\%. Maloneova procedura antegradne klizme (ACE procedura) je primenjena u 9 pacijenata. Ona je bila uspešna $100 \%$ u prvoj godini, sa komplikacijama u 44\% slučajeva (stenoza i kvašenje konduita).

Program tretmana creva nudi značajni boljitak deci sa fekalnom inkontinencijom nakon hirurškog lečenja ARA. Maloneova ACE procedura se može primeniti kod pacijenta nakon uspešnog programa tretmana creva. Premda su pacijenti sa ACE procedurom zadovoljni, procenat komplikacija je velik.

Ključne reči: anorektalna anomalija, ishod lečenja, tretman creva (bowel management), ACE procedura

\section{UVOD}

Anorektalne anomalije (ARA) predstavljaju širok spektar kongenitalnih poremećaja u razvoju završnog dela digestivnog trakta, veoma često udružene sa regionalnim anomalijama urogenitalnog trakta i sakruma, kao i drugim urođenim anomalijama. Klasifikacija ovih anomalija prema lokaciji i visini fistule između rektuma i urogenitalnog trakta kao i savremen pristup u operativnom lečenju počinje osamdesetih godina prošlog veka primenom posterio-sagitalnog pristupa (1). Od 1982. ova klasifikacija i operativna tehnika sa kojom je jasno vidljiva patološka anatomija anomalije omogućava preciznu operativnu rekonstrukciju. Posterio-sagitalni pristup je prihvaćena u svetu kao standardan način lečenja.
Na našoj klinici ovaj način operativnog lečenje se primenjuje od 1988. godine.

I pored korektne anatomske rekonstrukcije anomalije, fekalna inkontinencija i disfunkcija analnog sfinktera su često prisutne u ovih pacijenata i utiču na kvalitet života. Fekalna inkontinencija prati oko $25 \%$ pacijenata nakon lečenja anorektalnih anomalija (2). Deca sa fekalnom inkontinencijom imaju loš kvalitet života i kada postanu svesvni svog nedostatka mnogo pate. Osim inkontinencije, opstipacija je izuzetno čest funkcionalni poremećaj koji prati pacijente sa anorektalnim anomalijama u postoperativnom toku. Ukoliko se ne dijagnostikuje i ne leči adekvatno predstavlja ozbiljan funkcionalni problem pacijentu. Morbiditet koji proističe iz 
loše lečene opstipacije kod pacijenata sa ARA uključuje opstrukciju creva fekalnim masama, sekundarni megakolon i pseudoinkontinenciju $(3,4)$. Tretman creva (bowel management) je konzervativan način lečenja fekalne inkontinencije koji se uspešno sprovodi i poboljšava kvalitet života pacijenata $(5,6)$.

\section{Cilj RADA}

Analiza rezultata operativnog lečenja u svetlu postizanja fekalne i urinarne kontinencije i primena tretmana creva u poboljšanju kvaliteta života.

\section{MATERIJAL I METODE}

Retrospektivnim uvidom u kliničku i radiografsku dokumentaciju 224 pacijenta operisanih zbog anorektalnih anomalija u periodu 1988-2015 godine analizirane su operativne procedure, komplikacije i ishod lečenja. Fekalna i urinarna inkontinecija je evaluirana kod pacijenata starijih od 3 godine. Kriterijum za fekalnu kontinenciju je bila sposobnost da se dete spontano i kontrolisano prazni bez pomoći supozitorija ili klizme. Evaluacija urinarne kontinencije se zasnivala na sposobnosti deteta da spontano i kontrolisano u potpunosti prazni bešiku. Dva pacijenta koja su umrla pre, a dva nakon operacije otvaranja kolostome u periodu između 1988-1998, sa udruženim kompleksnim anomalijama nisu uzeta u razmatranje u ovoj studiji. U slučajevima fekalne kontinencije primenjen je tretman creva i praćen njegov ishod. U postoperativnom toku se pratila fekalna kontinencija i u slučajevima postojanja inkontinencije pacijenti uzrasta starijeg od 3 godine su uključeni u program tretmana creva. U zavisnosti od tipa motiliteta kolona, da li je motilitet usporen (opstipacija) ili hiperaktivan (dijareja) prilagođavao se tretman creva. Tretman creva se sastojao od dnevnih klizmi sa fiziološkim rastvorom ili hipertonim slanim rastvorom, uz dodatak glicerina ili parafina. Količina klizme i njena koncentracija je određivana putem pokušaja i greške. Klinički odgovor, tj. stepen pražnjena crvea je praćen radiografski kao i na osnovu rezultata. Dobar rezultat je smatran ako dete nakon klizme ima obilno pražnjenje creva i naredna $24 \mathrm{~h}$ ne prlja veš. U slučaju da je kolon hiperaktivan uz konstipativnu dijetu je dodavan loperamid. Deca su hospitalizovana 7 dana uz obuku majke da sprovode tretman creva. Nakon otpusta majke su vodile dnevnik o količini i sastavu date klizme i svakodnevnom rezultatu, tj. prljanju ili ne prljanju veša.

\section{ReZultati}

U našoj seriji lečili smo ukupno 224 pacijenta, od kojih 115 devojčica, od čega 26 sa kloakalnom anomalijom. U grupi dečaka lečeno je 109 pacijenata, od kojih 3 sa rektovezikalnom fistulom. Svi pacijenti su operisani posterio-sagitalnim, anteriosagitalnim ili transrektalnim pristupom (posterior kloake). U slučajevima rektovezikalne fistule kao i potrebe „vaginalnog switch-a“ pristupalo se kombinovano posterio-sagitalnim pristupom i laparotomijom.

Od 26 pacijenata sa kolakalnom anomalijom u 6 je postojala varijacija pod nazivom posterior kloaka. Sve devojčice sa posterior kloakom su imale akcesornu uretru, kod 4 je pristupljeno transanorektalnim pristupom, a kod 2 anterosagitalnim. Pet pacijenata sa klasičnom kloakom je zahtevalo laparotomiju, u tri slučaja je rađen ,vaginal switch“, a u 2 zamena vagine sa ilealnim konduitom. U 19 pacijenata sa kloakom je rađena totalna urogenitalna mobilizacija. Kloakalna anomalija je bila udružena sa hidrokolposom u 8 pacijenata, a u 7 je dijagnoza postavljena prenatalno. Kod svih novorođenčadi sa hidrokolposom i prenatalno postavljenom dijagnozom bile su prisutne duple Milerove strukture. Hidrokolpos je bio praćen udrulenom megaureterohidronefrozom u 8 novorođenih devojčica sa kloakom. Svim pacijentima sa hidrokolposom je rađena ili vaginalna drenaža (2) ili vezikostoma (6).

Reoperacija je rađena kod 1 pacijenta zbog pogrešno lociranog anusa. Vaginalna striktura je operisana u 2 devojčice nakon operacije kloakalne anomalije. Jedna rekurentna rektovaginalna fistulu nakon operacije atrezije anusa sa rektovestibularnom fistulom je zahtevala reoperaciju. Analna stenoza se javila u devojčice koja je razvila ulcerozni kolitis refrakteran na konzervativnu terapiju i za sada ima otvorenu ileostomu. U 13 pacijenata su rađene manje korekcije zbog prolapsa rektalne sluznice.

U našoj seriji od 224 operisana pacijent 52 (24\%) su bila fekalno inkontinentni. Lečenje je bilo operativno u 9 pacijenata kod kojih je učinjena Maloneova ACE procedura („antegrade continence enema”), a kod ostalih 43 je sproveden tretman creva („bowel management"). Operativno lečenje je sprovedeno kod pacijenata kod kojih je prethodno uspešno sprovođen „bowel managemet“. Tretman creva je uvek uspostavljen u bolničkim uslovima, pri čemu se odredjivala količina i sastav klizme (fiziološki rastvor, hipertoni slani rastvor, dodatak sapunice, glicerina, parafina) i dijeta, čime se postizalo da pacijent tokom naredna $24 \mathrm{~h}$ bude čist i u svom vešu bez pelena. Praćenje pražnjenja creva je vršeno nativnim radiografskim snimcima. Uspešnim se smatralo lečenje koje je omogućilo da pacijent $24 \mathrm{~h}$ nakon tretmana bude čist, tj. ne prlja veš. Majke su obučene za tretman creva. Pacijenti su periodično kontrolisani, a u međuvremenu su majke vodile dnevnik u koji su beležile neophodne podatke o načinu pražnjenja creva i prljanju veša. Inicijalno uspeh je postignut primenom tretmana creva u $39(90,6 \%)$ konzervativno lečenih pacijenta. Nakon odlaska kući i promene uslova u odnosu na bolničke, 
uspešnost je u prva 3 meseca nakon započinjanja konzervativne terapije smanjena na $83,7 \%$ (36 pacijenata). Evaluacija uspešnosti lečenja nakon 1 godine je bila $93 \%$ (40 pacijenata). Pacijenti koji su ušli u pubertet (stariji od 13. godina), su dostigli uspešnost lečenja od $95 \%$. Operativno lečeni pacijenti ACE procedurom su imali uspešnost $100 \%$ u prvoj godini lečenja. Komplikacije u vidu stenoze ili kvašenja oko stome su se javile u 4 (44\%) pacijenta. Stenoza je rešena dilatacijom, a kvašenje oko stome endoskopskim ubrizgavanjem kopolimera dekstranomer hijaluronične kiseline (Deflux paste).

Urinarna inkontinencija se lečila čistom intermitentnom kateterizacijom mokraćne bešike u 9 pacijenata, od toga transuretralno u 7 (sve devojčice), a kroz konduit po Mitrofanoffu u 2 slučaja.

\section{Diskusija}

I pored velikog napretka u operativnom lečenju kongenitalnih anorektalnih anomalija u poslednjih 30 godina, značajan procenat dece ima dugotrajne probleme sa fekalnom inkontinencijom, što prouzrokuje psihološke i socijalne probleme. Osim fekalne inkontinencije, koja se javlja u oko $25 \%$ do $30 \%$ pacijenata operisanih zbog anorektalnih anomalija, još oko $30 \%$ ovih pacijenata imaju druge funkcionalne poremećaje defekacije kao što su opstipacija, povremo prljanje veša i fekalna inkontinencija tokom perioda dijareje. Opstipacija je najznačajnija postoperativna funkcionalna komplikacija i javlja se u rasponu od $10 \%$ do $73 \%$. Opstipacija je povremeno praćena prelivanjem fekalnog sadržaja što dovodi do pseudoinkontinencije i prljanja veša.

Lečenje fekalne inkontinencije $\mathrm{u}$ dece operisane zbog anorektalnih anomalija podrazmeva razlikovanje dve grupe poremećaja (7). Prvu grupu pacijenata čine oni sa istinskom fekalnom inkontinencijom, koji nemaju voljno pražnjenje creva jer su rođeni sa tipom anomalije koja ima lošu prognozu (rektovezikalna fistula, kloaka sa zajedničkim kanalom dužim od $3 \mathrm{~cm}$, „tethered cord“, agenezija više od 2 sakralna pršljena). Drugu grupu pacijenata čine oni koji su rođeni sa anorekatalnom anomalijom koja ima prognostički dobru funkciju, ali izraženu opstipaciju koja je loše lečena, te su razvili pseudoinkontinenciju. Ova druga grupa nakon pražnjenja fekalnih masa i ispravne doze laksativa ima voljno pražnjenje develog creva i prestaje da prlja veš.

Tretman creva (bowel management), koji je započet pre 30 godina od strane Alberta Pene i Marka Levitta (8) je lako sprovodljiv u kućnim uslovima od strane roditelja, nije skup i ima uspešnost u $95 \%$ pacijenata (9). Naši rezultati su vrlo slični literaturi. Inicijalni uspeh tokom bolničke primene tretmana creva na kontrolu pražnjena je postignut kod 90,6\% pacijenata. I pored nešto manje uspešnosti po odlasku u kućne uslove $(83,7 \%)$, do porasta u kontro- lisanom pražnjenju dolazi već nakon prve godine primene ovog sistema, jer se porodica obuči da prati promene $u$ pražnjenju creva i izvrši sama potrebne korekcije. Nakon puberteta dolazi do poboljšanja fekalne kontinencije i u slučajevima visokih anomalija što se tumači nestankom opstipacije koja je glavni uzrok funkcionalnih problema u ranom uzrastu (10). Za razliku od ovih rezultata, ispitivanje funkcionalnih poremećaja i dugotrajnog kvaliteta života pacijenata sa visokim anorektalnim anomalijama od strane Hashisha i saradnika (11) je pokazalo da se obrazac pražnjena creva pogoršava sa uzrastom. Međutim ovi pacijenti nisu bili u programu tretmana creva. $U$ našoj seriji primene tretmana creva imali smo uspešnost od 95\% nakon puberteta, što je posledica mnogo manje izražene opstipacije, ali i motivisanosti samog pacijenta da se pridržava programa tretmana creva. U nastojanju da se pacijenti u programu tretmana creva osamostale u procesu davanja klizmi, Malone je 1990. promenom smera davanja klizme, antegradnim putem, (ACE procedura) kroz apendix, omogućio efikasnije pražnjenje creva (12). Ova metoda se od tada uspešno primenjuje u lečenju fekalne inkontinencije različite etiologije (13). U slučajevima kada uz fekalnu postoji i urinarna inkontinencija primenjuju se operativne tehnike po Mitrofanoffu (14) i Montiju (15) za obezbeđivanje antegradnog puta čiste intermitentne kateterizacije mokraćne bešike. Procedure se razlikuju prema tkivu koje se koristi za konduit preko koga se vrši kateterizacija bešike. U slučaju procedure po Mitrofanoffu konduit je apendiks, a po Montiju segment tankog creva. Bez obzira da li se koristi samo ACE procedura ili u kombinaciji sa konduitom za kateterizaciju bešike (procedura po Mitrofanoffu ili Montiju) komplikacije su česte (57\%). Najčešća komplikacija je stenoza stome (41\%), kvašenje u predelu stome, perforacija cekuma zbog otežane kateterizacije. U našoj seriji smo imali ukupno $44 \%$ komplikacija, ali je mali broj pacijenata lečen na ovaj način.

\section{ZaKLJUČAK}

Anorektalne anomalije još uvek predstavljaju najsloženije kongenitalne anomalije gastrointestinalnog trakta s obzirom da zahvataju više sistema. Za lečenje komplikovanih visokih anomalija potreban je iskusan i obučen tim. S aspekta funkcionalnog rezultata lečenja najsloženije anomalije i dalje imaju lošu prognozu u smislu fekalne i urinarne kontinencije. Primenom sistema tretmana creva može se postići kontrolisano pražnjenje i socijalna integracija između $90-95 \%$ pacijenata. Urinarna kontinencija je mnogo ređe ugrožena, ali ukoliko postoji neminovna je intermitentna čista kateterizacija bešike.

Program tretmana creva nudi značajni boljitak deci sa fekalnom inkontinencijom nakon hirurškog lečenja ARA. Maloneova ACE procedura se može primeniti kod pacijenta nakon uspešnog programa tretmana creva. Premda su pacijenti sa ACE procedurom zadovoljni, procenat komplikacija je velik. 


\section{Literatura}

1. Pena A, de Vries PA: Posterior sagittal anorectoplasty: Important tecnical consideration and new applications. J Pediatr Surg, 1982, 17:797-811

2. Pena A: Anorectal malformations. Semin pediatr Surg 1995, 4:35-47.

3. Levitt MA, Pena A: Imperforate anus and cloacal malformations. In Pediatric Surgery, $5^{\text {th }}$ ed. Holcomb GW \& Murphy JP (ed) Elsevier Saunders, Philadelphia, 2010, 337-59

4. Levitt MA, Kant A, Pena A: The morbidity of constipation in patients with anorectal malformations. J Pediatr Surg, 2010 45:1228-1233

5. Pena A, Guardino K, Tovilla JM, Levitt MA, Rodriquez G, Torres R: Bowel Management for Fecal Incontinence in Patients With Anorectal Malformations. J Pediatr Surg, 1998,33:133-137

6. Bischoff A, Levitt MA, Bauer C, Jackson L, Holder M, Pena A: treatment of fecal incontinence with a comprehensive bowel management program. J Pediatr Surg, 2009, 44:1278-1284

7. Colares J, Purcaru M, Da Silva G, Frota M, Da Silva C, Melo-Filho A, Bischoff A, Pena A: Imapct of the Bowel Management program on the quality of life in children with fecal incontinence. Pediatr Surg Int, DOI 10.1007/s00383-016-3874-5, 2016, Feb. 13(1-6)
8. Bischoff A, Tovilla MA: A practical approach to the management of pediatric fecal incontinence. Semin Pediatr Surg, 2009, 19:154-159

9. Bischoff A, Levitt MA, Pena A: Bowel management for the treatment of pediatric fecal incontinence. Pediatr Surg Int, 2009, 25:1027-1042

10. Rintala RJ, Lindahl HG: Fecal Continence in Patients Having Undergone Posterior Sagittal Anorectoplasty Procedure for a High Anorectal Malformation Improves at Adolescence, as Constipation Disappears. J Pediatr Surg, 2001,36(8): 1218-1221.

11. Hashish MS, Dawoud HH, Hirschl RB, Bruch SW, Batarny AM, Mychaliska GB, Drongowski RA, Ehrlich PF, Hassaballa SS, El-Dosuky NI, Teitelbaum DH: Long-term functional outcome and quality of life in patients with high imperforate anus. J Pediatr Surg, 2010, 45: 224 230.

12. Malone PS, Ransley PG, Kiely EM: Preliminary report: the antegrade continence enema. Lancet, 1990, 336:1217-1218

13. Malone PS, Curry JI, Osborne A: The antegrade continence enema (ACE) procedure why, when and how? World J Urol, 1998, 16:274-278

14. Mitrofanoff P: Cystostomie continent trans-appendiculaire dans le traitement des vessies neurologiques. Chir Pediatr, 1980, 21:297-305

15. Monti PR, Lara RC, Dutra MA, deCarvalho JR: New technicques for construction of efferent conduits based on the Mitrofanoff principle. Urology,1997, 49:112-115 